\title{
PAISAJES CAMBIANTES: LA DOMINACIÓN INKA EN EL VALLE CALCHAQUÍ NORTE (ARGENTINA)
}

\author{
Félix A. Acuto*
}

\section{La Arqueologia Inka}

Los arqueólogos dedicados al estudio de la problemática inkaica por lo general han centrado sus investigaciones alrededor de ciertos temas, dejando otros de lado. A grandes rasgos se puede decir que los objetivos de las investigaciones en la arqueología Inka han apuntado a aspectos como:

a) El estudio de la economía política imperial y su influencia sobre las economías de los grupos dominados. Especialmente lo que respecta a: la organización institucional, las relaciones de producción, el sistema de tenencia de tierras, las relaciones sociales de intercambio entre el Estado y las poblaciones subordinadas y el estudio de las características de las políticas de financiamiento que el Imperio Inka generó con el fin de obtener la energía necesaria para sostener y reproducir la maquinaria estatal.

b) Las políticas imperiales de traslado de poblaciones, denominadas mitimaes, desde sus lugares de orígenes a otros destinos para servir a los intereses del Estado Inka en alguna otra región del Imperio: ya sea como soldados, artesanos, funcionarios (élite) representando al Imperio en alguna provincia etc.

c) Estudios sobre la cultura material Inka: cerámica, tejidos, metalurgia, arquitectura, caminos.

Con respecto a este último campo de investigación, sin duda fue uno de los que mayor interés tuvo para los arqueólogos, ya que las características

(*) CONICET - Instituto de Cs. Antropológicas, Sección Arqueología, Facultad de Filosofía y Letras, Universidad de Buenos Aires. particulares de la cultura material inkaica (sobre todo la arquitectura y la cerámica) han servido para determinar la presencia imperial en una región (Hyslop 1993).

Los rasgos típicos de la arquitectura y el patrón de asentamiento inkaico han sido uno de los temas más abordados, sobre todo por los arqueólogos argentinos (González 1980; Raffino 1978, 1981; Raffino et al. 1979-82). Estas investigaciones se han centrado fundamentalmente en caracterizar los edificios típicamente inkaicos (realizándose tipologías), así como las técnicas constructivas. Así también, por lo general se han estudiado los asentamientos imperiales, creándose tipologías y clasificándolos de acuerdo a aspectos como su ubicación en un territorio, las facilidades que presenta (incluyendo tipos de edificios) y su tamaño (en relación a los otros sitios de la región); tal como: 1) Centros Administrativos, caracterizados por la presencia de espacios públicos, plazas, edificios de carácter administrativo y ceremonial (kallanka, ushnu, almacenes o qollcas), cercanos a caminos principales y en algunos casos con un diseño en la organización del espacio que replicaba al Cuzco, la capital del Imperio (Hyslop 1990); 2) Enclaves de Producción, por ejemplo para la producción metalúrgica, agrícola, cerámica; 3) Tambos o estaciones de paso, a la vera del camino y a un día uno de otro, por lo general de tamaño reducido; 4) Fortalezas, ubicadas generalmente cerca de las fronteras; 5) Santuarios de Altura, en las cumbres de altos cerros, usualmente a más de 5.000 metros de altura, con plataformas, sacrificios humanos y ofrendas.

Estos análisis sobre el patrón de asentamiento realmente nunca superaron el plano descriptivo, y como muchas tipologías, han ocultado la variabilidad de las situaciones, dándole al imperio una cierta homogeneidad ficticia. Un asentamiento era incluido en algún tipo, y esto era ya suficiente para 
conocer su función, dejándose de lado algún tipo de trabajo arqueológico más profundo (Acuto 1996). Esto se ve claramente reflejado en los pocos sitios inkaicos que han sido trabajados sistemáticamente en Argentina, con análisis del espacio más profundos y con excavaciones continuas. Es decir, las investigaciones sólo se centraron en estudios funcionalistas clásicos de patrón de asentamiento, realizándose tipologías de sitios y viendo que tipo de sitios instalaron los Inkas en una región.

De este modo, no sólo fueron pocos los sitios inkaicos excavados (ver Williams 1983, 1991; Bárcena 1988 como una de las pocas excepciones) con el objeto de determinar las actividades concretas que el Imperio allí efectuó, sino también la problemática de la estructuración social del espacio fue ignorada para sólo caracterizar qué clases de asentamientos se habían construido en una región. Así también, la relación de la ubicación de los sitios Inkas y los locales, por lo general nunca se planteó como una problemática de demasido interés, tratando de buscar explicaciones al respecto.

El objetivo de este trabajo es exponer algunas interpretaciones preliminares sobre la ocupación e instalación Inka en el valle Calchaquí Norte (Salta, Argentina) y los valles y quebradas aledañas, desde un punto de vista de la construcción y estructuración de los paisajes sociales, y de qué manera ésta afectó a la ocupación previa. Mi estudio se centrará en la superposición que se produjo, con la llegada de los Inkas a la región, entre el paisaje social de las comunidades locales y el paisaje contruido por el Imperio. Especialmente cómo el paisaje de poder cambió de uno a otro período.

\section{Espacio y estructuración social}

En las últimas décadas la Teoría Social se ha visto enormemente enriquecida con la incorporación de la dimensión espacial en sus teorizaciones sobre lo social. Se comenzó a ver la conexión entre relaciones sociales y estructura espacial, y ya no sólo al espacio como un simple contenedor en donde éstas se daban, sino como un medio a través del cual las relaciones sociales se producen y reproducen (Lefebvre 1974; Giddens 1979, 1981, 1995; Gregory y Urry 1985 (eds.)).

La espacialidad (o el espacio socialmente construido) es un producto social y una parte integral de la constitución material y la estructuración de la vida social (Soja 1985). La espacialidad, por estar socialmente producida, debe ser distinguida del espacio físico de la naturaleza, y por ser material deber diferenciarse del espacio mental de la cognición y la representación. Por supuesto estos tres tipos de espacios están estrecha y dialécticamente relacionados en un proceso complejo que Soja (1996), citando a Lefebvre (1974) denomina como Trialéctica del Espacio.

La espacialidad puede estar continuamente reforzada o reproducida a través del tiempo, presentando una apariencia de estabilidad y persistencia. Pero también puede ser substancialmente re-estructurada y radicalmente reconstituida. $\mathrm{La}$ espacialidad y la temporalidad se intersectan en un proceso social complejo que crea una secuencia histórica de espacialidades que evolucionan gradualmente, una estructuración espacio-temporal de la vida social que da forma no sólo a los grandes movimientos del desarrollo social, sino también a las prácticas recursivas de las actividades cotidianas (Soja 1985: 94).

Acciones sociales construyen espacialidades, pero a su vez éstas construyen a las acciones sociales a través de su materialidad y sus significados. La estructura espacial no es sólo la arena donde las relaciones sociales se expresan sino el dominio donde, y a través del cual, dichas relaciones se constituyen. Así, la reproducción del espacio (y la construcción de la historia) resultan ser tanto el medio como el resultado de la acción y las relaciones sociales. Esta dualidad de estructuración espaciotemporal conecta a las estructuras sociales y espaciales de un modo en que las primeras aparecen concretizadas en las segundas, esto es: las estructuras y las relaciones espaciales son la forma material de la estructura social y las relaciones sociales. $\mathrm{La}$ vida social está materialmente constituida en su espacialidad (Soja 1985:94).

Un aspecto clave de la producción y de la reproducción de las espacialidades es su carácter conflictivo. Se trata de un proceso que implica conflicto social debido a que una espacialidad, a partir de su materialidad y los significados en ella impresos, produce y reproduce relaciones de dominación, resultando ser por lo tanto un instrumento de poder (Lefebvre 1974). El espacio está cargado de ideología. La producción y reproducción de las espacialidades implica una lucha por la imposición de sentidos sociales y de un determinado tipo de discurso simbólico y material sobre cómo debe ser el or- 
ACUTO, F.A. Paisajes cambiantes: la dominación Inka en el valle Calchaquí Norte (Argentina). Rev. do Museu de Arqueologia e Etnologia, São Paulo, Suplemento 3: 143-157, 1999.

den social. La imposición de sentidos, y de un tipo de discurso social sobre otros, implica la dominación de un grupo social (el que lo impone) sobre otro (el que lo acepta como el orden legítimo). La producción y reproducción de una espacialidad no sólo implica procesos de dominación sino también de resistencia (Miller et al. 1989). Si bien sí existe un discurso "oficial" y "legítimo" (Bourdieu 1985), también existen significados y discursos alternativos en competencia, que se construyen simultáneamente y que, en algunes casos, se tratan de imponer.

De este modo, concibo que el espacio es manipulado como mecanismo de reproducción de ciertas prácticas y relaciones sociales (reproducción del poder de unos grupos sobre otros) y como mecanismo de control social. La construcción del espacio ayuda a fijar el orden social, y es manipulada por grupos o facciones que detentan parte del poder social para fijar ciertos significados y transmitir ciertos mensajes. La materialidad de la espacialidad o el ambiente construido (built environment) no sólo expresan sino que también orientan y dan forma al proceso social, especialmente en lo que respecta a la sociabilidad y al control de los comportamientos sociales (Hillier y Hanson 1984; Lawrence y Low 1990; Parker Pearson y Richards 1994). A través del uso del espacio y de las estructuras arquitectónicas se crean y transmiten principios sociales (Locock 1994). La producción y reproducción de las espacialidades constituyen a la vida social, contribuyendo sobre todo a producir y reproducir relaciones de poder y dominación de unos grupos sobre otros (ver por ejemplo Foucault 1976).

Existen ciertos mecanismos empleados para dominar, por ejemplo el control de la circulación y la visión implica dominación, los límites en el espacio y la clausura en los accesos y en la circulación crean asimetrías en el poder (Foster 1989a y 1989b; Thomas 1993; Smith y Adams 1995). Así, el espacio está ideológicamente construido para afectar la percepción que hay sobre éste y legitimar las relaciones sociales. La creación de límites como rasgos físicos se suele asociar a necesidades de defensa, territorio, protección y contención. Las entradas y las barreras físicas (tal como paredes) marcan las diferencias entre dominios y así el acceso restringido y controlado entre éstos. Dividiendo físicamente y demarcando el espacio clasificamos y controlamos los lugares y las relaciones. Las paredes, los pasajes y las entradas sirven para marcar la transición entre dominios como: adentro/afuera, sagrado/profano, hombre/mujer, público/ privado, enemigo/amigo, élite/común, iniciado/no iniciado. Existen también otros límites que no son físicos sino perceptuales o conceptuales (Parker Pearson y Richards 1994: 24).

La espacialidad es una manifestación real de las relaciones sociales, más que su simple reflejo. Además, hay que destacar que el espacio social, históricamente constituido, resulta ser la dimensión en donde la sociedad se reproduce, así también es el lugar desde donde se puede actuar sobre la sociedad y transformarla.

De esta manera, no veo al espacio social como algo pasivo y funcional o como el contenedor de la sociedad, sino que para mi la construcción del espacio y la creación de paisajes sociales actúan activamente sobre el proceso social, siendo construidos por la sociedad pero a la vez siendo un medio de fundamental importancia en la construcción y la estructuración de la sociedad, generando determinadas acciones, prácticas y relaciones sociales, así como reproduciéndolas.

En resumen, a partir de estas nuevas conceptualizaciones sobre el rol del espacio en la dinámica de la vida social, la Teoría Social comenzó a tener en cuenta que las interacciones sociales se desarrollan en un espacio o en escenarios determinados. Los actores usan esos escenarios de manera consuetudinaria y táctica para dar sustento a un sentido en actos comunicativos. La repetición del uso de un escenario fija la interacción social, reproduciéndola. Una regionalización espacio-temporal normalmente implica una fijeza social (Giddens 1995:26). Los escenarios de interacción (un barrio, una escuela, una casa etc.), a través de su materialidad y de los mensajes simbólicos impresos en dicha materialidad, ayudan a fijar cuales son el tipo de prácticas sociales y relaciones que los agentes deben o pueden establecer en dichas localizaciones. La experiencia de los actores sociales y la rutinización de las prácticas que ellos realizan les permiten ser agentes competentes, que saben como comportarse o relacionarse en un determinado escenario.

\section{Paisaje}

Sin duda dos de los conceptos que más ampliamente han sido usados en ciencias sociales, principalmente en geografía, son los de lugar (place) y paisaje (landscape). Por supuesto que su significado vario, y han sido constantemente rede- 
finidos a lo largo de la historia de esta disciplina (Barnes y Gregory 1997, Entrikin 1997, Crosgrove 1997, Rose 1997). Sin embargo, varias de estas definiciones coinciden en parte en caracterizarlos como los espacios que no sólo se perciben, sino que también se experimentan, se aprenden y se viven. Por lo general, se ha concebido al paisaje como una forma de ver, un punto de vista ideológicamente constituido (Rose 1997).

En mi caso entiendo que la construcción social y cultural (material y cognitiva) del espacio produce lugares y paisajes: dos tipos de espacialidades. Así, un paisaje no sólo se construye materialmente en un espacio físico, sino también en las mentes de los actores sociales.

No es suficiente enfocar sólo las formas materiales o visibles del paisaje, hay que intentar visualizar las relaciones y acciones sociales que los constituyeron. Más que definirse por su materialidad, el paisaje es concebido como un sistema de signos y símbolos visuales (iconografía) del discurso culturalmente predominante y de las relaciones de poder. Aunque la interpretación de los artefactos materiales es importante, la tarea central es ir un paso atrás e interpretar el sistema social más amplio y las relaciones culturales en las que el significado de los artefactos se constituye (Barnes y Gregory 1997: 296). Esto es fundamental, ya que la materialidad sola puede ser engañosa, puede actuar ideológicamente representando un proceso social diferente al real, por ejemplo, disfrazando contradicciones, conflictos, dominación, etc. (McGuire 1991).

El espacio socialmente construido forma paisajes que pueden tener distintas escalas espaciales; por ejemplo en la actualidad un paisaje puede ir desde un pueblo o ciudad, un valle, un país o el planeta entero.

Los paisajes están cargados de sentido, tienen significado y transmiten mensajes no verbales a los agentes que en él interactúan. Los paisajes transmiten mensajes a través de su materialidad, la cultura material presente en un paisaje es significativa, comunicando simbólicamente a los actores sociales cual es el tipo de comportamiento, las clases de prácticas y relaciones sociales que se pueden y deben realizar y establecer en ese escenario particular en determinado momento. El paisaje es sumamente activo en la creación de desigualdades sociales debido a que, a través de su materialidad y su significado, puede habilitar o clausurar (Weber 1997) ciertas prácticas y relaciones de manera diferencial entre los individuos y grupos sociales de una misma sociedad. El paisaje actúa en cierto sentido como un mecanismo cultural que ayuda a crear las identidades de las personas que se ven insertas en él. Asimismo el paisaje social en un determinado momento puede ser reflejo de una ideología dominante y variar cuando esta cambia (McGuire 1991).

Paisaje no sólo denota el significado geográfico usual de "alrededores físicos" (o el trabajo de la cultura sobre el paisaje natural), sino también se refiere a un ensamble de prácticas materiales y sociales y su representación simbólica. En un sentido más estrecho, paisaje representa la arquitectura de las relaciones de clases sociales, el género y las relaciones raciales impuestas por las instituciones de poder. En un sentido más amplio connota el panorama completo que vemos: tanto el paisaje de los poderosos como el de los subordinados (Zukin 1990:16). Así, podemos decir que los paisajes están modulados por relaciones de poder, dominación, conflicto y resistencia.

Es importante destacar que un paisaje no presenta un significado homogéneo entendido por todos los agentes sociales, sino que más bien existe al mismo tiempo una superposición de los significados que cada grupo social o cultural, clase o facción le imprime a ese paisaje (Bender 1993). De este modo, un paisaje, en un momento histórico determinado, puede presentar diferentes significados para distintos grupos. A su vez, estos mensajes distintos que cada grupo decodifica en el paisaje implican distintas prácticas y tipos de relaciones sociales que cada cual va a establecer en ese espacio social.

Ahora, si bien existen múltiples significados impresos sobre un mismo paisaje social en un mismo momento histórico, no todos los significados (y por lo tanto no todas las prácticas y relaciones sociales que esos mensajes no verbales habilitan) son los legítimos (Bourdieu 1985). Los grupos de poder social $^{1}$ son los que establecen y tratan de imponer el significado legítimo que fije determinadas conductas sociales vinculadas directamente con sus intereses de control y dominio sobre el resto de la sociedad. Se trata de gobernar a través de la

(1) Es importante destacar que cuando me refiero a los grupos que detentan alguna clase de poder no sólo me refiero a nivel más macro, como puede ser un poder político o el poder de un estado, sino a también a niveles micro como las estructuras de poder en una unidad doméstica o en las relaciones de género. 
ACUTO, F.A. Paisajes cambiantes: la dominación Inka en el valle Calchaquí Norte (Argentina). Rev. do Museu de Arqueologia e Etnologia, São Paulo, Suplemento 3: 143-157, 1999.

materialidad la variación de los significados culturales, la cultura material inserta en el paisaje ayuda a fijar significados. Existe conflicto de intereses entre distintos grupos e individuos en el proceso de institución de significados, a partir de la búsqueda del control y el dominio de la sociedad (Hodder 1994). Así, los individuos usan la cultura material socialmente, para negociar su posición en la sociedad y para producir el cambio social (Hodder 1994:22). Sujetos bien situados pueden manipular la cultura material como recurso y como sistema de señales para crear y transformar relaciones de poder y de dominación (Bourdieu 1977, Giddens 1979, Shanks y Tilley 1987). De todos modos, si bien existe un significado dominante, la estructura social habilita (Giddens 1995) la construcción de significados alternativos sobre un mismo paisaje.

Sería interesante graficar un poco este punto. Existe en Buenos Aires una sección de una calle céntrica, llamada Florida, que está compuesta por edificios de oficinas, bancos, negocios relacionados con estas actividades y restaurantes y cafés orientados a la gente que allí trabaja, de lunes a viernes durante el día. Entre estos actores sociales se establecen cierto tipo de prácticas y relaciones sociales, la gran mayoría relacionadas con actividades de tipo comercial y financiero, que implican una forma determinada de comportarse, de vestirse y de usar el cuerpo, estrechamente relacionada con el mundo de negocios del capitalismo contemporáneo. Entre las 6 y las 7 pm, y una vez concluido el horario de trabajo bancario y de oficina, empiezan a llegar a esa zona otros actores sociales que actúan durante la noche. Se trata de personas de bajos recursos económicos o sin hogar que se acercan a esta calle céntrica para revisar y apropiarse de la gran cantidad de basura que en ésta se produce, y para buscar en las entradas de los edificios y negocios un lugar donde pasar la noche y dormir. Lo que buscan entre los desechos producidos durante el día es cartón para vender y restos de comida para alimentarse. ${ }^{2}$ De esta manera, un mismo espacio

(2) Muchos de los restaurantes que allí funcionan (que sólo lo hacen de día), descartan gran cantidad de alimentos sin consumir y en muy buen estado pero que no están suficientemente frescos como para dárselos a la gente que viene a esta zona durante el día. Uno de los restaurantes más frecuentados por los "homeless" son los de comida rápida como McDonald's ya que es en el mismo en donde se puede encontrar más cantidad de alimentos. contruido presenta dos significados, o es decodificada de manera distinta por dos grupos de la misma sociedad. Para los agentes sociales que lo frecuentan durante las horas diurnas de los días laborables, este espacio tiene un significado que los lleva a establecer cierto tipo de prácticas e interacciones sociales: trabajo de oficina, 40 minutos para comer al mediodía, el uso de ropa formal, tramites bancarios, negocios. Esa misma espacialidad, y esa misma cultura material, tiene otro sentido para los habitantes de la noche: un lugar para dormir y para poder obtener, de los desechos dejados por los agentes que transcurren en ese espacio durante el día, bienes que permitan su subsistencia. Así mismo, seguramente los actores que aprovechan este paisaje durante la noche deben establecer ciertas prácticas $\mathrm{e}$ interacciones con sus propias particularidades, tal como por ejemplo: acceso diferencial a la basura de ciertos lugares y a los mejores espacios para poder dormir por parte de un grupo, algún tipo de jerarquización interna etc.

Por supuesto que en este caso, estos dos conjuntos de significados impuestos sobre este lugar particular del paisaje urbano no tienen el mismo valor. El sentido que tiene esta calle durante el día es el legítimo y "oficial" el impuesto desde las estructuras centrales de poder. El sentido que cobra este lugar durante la noche es alternativo, no se desarrollan en este tiempo las prácticas y relaciones legítimas, las oficiales, sino ciertos comportamientos e interacciones que se asientan entre los intersticios de la estructura social. De este modo, se puede ver que una misma espacialidad, ya se trate de un paisaje o de un lugar específico, pude ser entendida, percibida y experimentada de manera distinta por distintos grupos sociales de una misma sociedad, según su posición social y económica, identidad cultural, clase, facción, género, edad, etc. (Bender 1993, Edholm 1993).

Si un paisaje (como espacio social e históricamente constituido) está materializado y cargado de significados, y si bien lo material permanece fijo durante períodos de tiempo más largos, mientras existen significados sociales distintos para esa misma materialidad durante ese período; se podría decir entonces que en cierto sentido existiría en un mismo espacio físico "paisajes superpuestos" Considero que los agentes de una misma sociedad y de un momento histórico específico, se mueven y son competentes para actuar en varios de esos "paisajes superpuestos", y decodificar los mensajes 
que la cultura material les transmite, pero no en todos. Sí existe un significado que todos conocen y una percepción del paisaje que todos tienen en algún grado, éstas son las que están fijadas desde las estructuras de poder social. En mi opinión, todos los agentes están más o menos capacitados para percibir, decodificar los mensajes e intervenir en las prácticas y relaciones que se establecen en el "paisaje impuesto" desde las estructuras sociales de poder, debido a que este paisaje es el que cuenta con los mecanismos de producción y reproducción en mayor número y tal vez eficacia.

Por otro lado, un mismo individuo o un mismo grupo social pude tener distintas percepciones en tensión, o entender y decodificar de distintas maneras una misma espacialidad. Es decir, un mismo paisaje puede contar con distintos significados al mismo tiempo para un mismo individuo o grupo (Bender 1993). La constitución de estas percepciones en tensión de una misma espacialidad se construyen social y colectivamente pero a distintas escalas. Por ejemplo, a una escala reducida de relaciones sociales más estrechas (parentesco, amistad), un lugar como un barrio en un paisaje urbano puedo entenderlo y percibirlo como mi lugar de pertenencia, el lugar de mis afectos. A una escala social mayor, que implique relaciones con toda la comunidad y sus instituciones, tal vez ese barrio sea visto como un lugar de pobreza y marginalidad. Yo, como parte integrante de mi sociedad conozco ese significado de marginalidad, pero ese mismo lugar también tiene para mi otros sentidos (la familia, mis seres queridos, mi infancia etc.) muy diferentes a los que pueden estar connotados con marginalidad. De este modo, mi identidad está construida a través de mi espacialidad y su significado. Además mi identidad está construida desde adentro de mi lugar y de mi grupo de pertenencia y desde afuera, el resto de la sociedad.

Sin duda, lo que permite a los agentes ser competentes en sus comportamientos en un paisaje es la experiencia (Edholm 1993). Los paisajes se conocen y decodifican sus símbolos, no sólo porque el agente pueda pertenecer a esa cultura y a ese tiempo, sino también (y muy importante) a través de la experiencia y la rutinización de las prácticas en esos escenarios. La experiencia y la rutina da competencia y habitus sensu (Bourdieu 1977).

La interacción social y la experiencia directa sobre un paisaje le permite a los agentes sociales conocer, no sólo donde están ubicados los diferentes recursos, sino también (y más importante) cua- les son los espacios donde se concentra el poder, cuales son los lugares públicos, sagrados, privados, domésticos. Se podría decir que los individuos tienen mapas mentales o imágenes espaciales sobre el espacio inmediato en donde viven, así como mapas de espacios mayores que pueden conocer, aunque tal vez no por experiencia directa. Mapas sobre los lugares y sus significados, las prácticas que deben y pueden fijar y las relaciones que deben entablar. Aquí se establece una dualidad dialéctica: las estructuras mentales de algunos actores sociales construyen a los paisajes, les dan su materialidad, pero a su vez la materialidad de los paisajes construye a las imágenes y las acciones sociales de muchos otros agentes de la misma sociedad.

Así, el paisaje exhibe signos materiales (y perceptuales) que generan prácticas y señalan que conductas son las correctas para un espacio y un momento determinado. Los actores sociales son capaces de decodificar los mensajes que le transmite sus paisajes y actuar en consecuencia, sobre todo los significados "legítimos" Son competentes para moverse en ese paisaje de la manera esperada y también pueden ser capaces de subvertir el orden y resistir. Entre los resquicios que deja el poder pueden generar prácticas y relaciones que no son las socialmente esperadas. Así como son competentes para actuar de la manera esperada, también son capaces de resistir. De este modo, un paisaje no es algo inerte, es un producto social en constante tensión y cambio (Bender 1993).

En conclusión, la construcción de un paisaje crea un sistema de sentidos que promueve las acciones adecuadas para un espacio particular; en otras palabras, mensajes simbólicos o codificados en la cultura material sirven como las guías subyacentes para las prácticas sociales (Steadman 1996). De este modo, el paisaje actúa en cierto sentido como un "ayuda memoria" social (Küchler 1993).

Hasta aquí me he referido principalmente a la lucha por la imposición de sentido en el paisaje, pero existe un punto muy importante que tocare brevemente: ¿quién construye una espacialidad o un paisaje?, ¿quién o quiénes lo materializan físicamente? Sin duda los grupos de poder social son los que tienen más capacidad de producir un paisaje y de establecer el lugar y el orden de la cultura material en él inserta. Sin embargo, otros grupos sociales, no sólo imponen significado al paisaje, sino que también tienen cierta capacidad de manipular a su favor la cultura material allí presente, $\mathrm{e}$ inclusive ser diseña- 
ACUTO, F.A. Paisajes cambiantes: la dominación Inka en el valle Calchaquí Norte (Argentina). Rev. do Museu de Arqueologia e Etnologia, São Paulo, Suplemento 3: 143-157, 1999.

dores y productores de la materialización del espacio socialmente construido (Paynter y McGuire 1991, Jarman 1993, Edholm 1993).

\section{La ocupación Inka en el valle Calchaquí Norte}

Durante su ocupación en el valle Calchaquí Norte, ${ }^{3}$ y los valles y quebradas asociadas, el Imperio Inka (Tawantinsuyu) empleó estrategias marcadamente distintas (De Lorenzi y Díaz 1976, D’Altroy et al. ms.). En la parte norte de esta región, especialmente en el valle del río Potrero (un tributario del río Calchaquî), los Inkas construyeron sus principales sitios. Dichos asentamientos son los que presentan la mayor inversión de infraestructura imperial (en cuanto a técnicas y calidad constructiva) de la región, una organización del espacio y edificios de estilo típicamente inkaicos, ${ }^{4}$ presencia de almacenes estatales etc. Por ejemplo, en el valle del río Potrero se encuentran: Apacheta Ingañan (SSalRol 8), Corralito (SSalRol 12), Capillas (SSalRol 9), Corral Blanco (SSalRol 10), Ojo de Agua, Potrero de Payogasta (SSalCac 42) y Cortaderas (SSalCac 65). ${ }^{5}$ Resulta interesante resaltar que en particular esta serie de sitios, que se ubican a lo largo de la ruta imperial que une la quebrada del Toro (a la altura del sitio arqueológico de Tastil) con el valle Calchaquí, fueron establecidos en territorios en donde la ocupación local tardía, sobre todo la presencia de centros poblacio-

(3) Se trata de una región del noroeste Argentino, con una altitud que varía, en el fondo de valle, entre los 3500 en sus nacientes a $1680 \mathrm{msnm}$ en su tramo inferior. Presenta un ambiente semiárido, con precipitaciones principalmente estivales que oscilan entre 100 y $200 \mathrm{~mm}$ anuales o menos. El clima suele rondar en los $15^{\circ}$ centígrados con radiaciones e irradiaciones solares intensas y grandes amplitudes térmicas entre el día y la noche. Las tierras de cultivos se limitan a los terrenos cercanos a los cursos permanentes de agua.

(4) A lo largo de su Imperio los Inkas instalaron centros administrativos regionales que replicaban en su organización espacial al Cuzco (Hyslop 1990), la capital del Tawantinsuyu. En este sector norte del valle Calchaquí, Potrero de Payogasta es el asentamiento que tendría estas características.

(5) Por el momento dejo de lado la caracterización de la ocupación Inka y local en el norte del valle Calchaquí propiamente dicho, es decir en los alrededores del poblado actual de La Poma, por no contar con adecuada información al respecto. nales grandes, fue prácticamente nula (Hyslop y Díaz 1983, Hyslop 1984).

Por su parte, en el sector medio del valle Calchaquí, que por otro lado es el área en donde existe la mayor concentración de asentamientos locales tardíos (y los de mayor tamaño), la ocupación Inka se reconoce a partir de la instalación de pequeños sectores con arquitectura imperial establecidos directamente sobre asentamientos locales pre-existentes (por ejemplo: La Casa Morada de La Paya (SSalCac 1) y Guitián (SSalCac 2) en el valle Calchaquí y Loma del Oratorio (SSalCac 8) en la quebrada de las Cuevas en la región de Cachi Adentro) o por la presencia de restos muebles inkaicos, usualmente cerámica y objetos de metal (por ejemplo: Tero (SSalCac 14) y Fuerte Alto en los alrededores de Cachi, Choque (SSalCac 17) en la margen izquierda del río Las Arcas en la región de Cachi Adentro y Valdez (SSalCac 12) en la margen oriental del valle Calchaquí, entre otros).

De esta manera, se puede afirmar que en los sectores medios de la región la materialización de la ocupación Inka, en relación a asentamientos y facilidades imperiales instaladas, es sumamente reducida comparada con aquella que se produce en el sector norte, especialmente en el valle del río Potrero (Figura 1).

Por lo que sabemos hasta ahora (D'Altroy et al. ms., Williams et al. 1995, Acuto 1994), además de las diferencias señaladas en cuanto a las estrategias de ocupación, también existieron diferencias en las actividades desarrolladas por el Imperio en uno y otro sector de la región. Hasta el momento podemos asegurar que los Inkas concentraron sus almacenes en este sector norte, lo que podría estar significando que una importante proporción de las actividades desarrolladas y financiadas por el Imperio en la región fueron efectuadas principalmente en esta área. Esto teniendo en cuenta que por lo general los almacenes, principalmente aquellos que contienen alimentos, se localizan cerca de los lugares en donde dichos bienes de subsistencia van a ser consumidos. También, en los asentamientos de este sector norte de la región se habrían desarrollado un gran número de actividades orientadas hacia la economía política estatal, tal como la producción metalúrgica y la confección de bienes suntuarios (Earle 1994). Por otra parte, la infraestructura instalada también sugiere que esta área tuvo una mayor relación con actividades ceremoniales y diplomáticas, tal como sucede en el sitio de Potrero de Payogasta. 
ACUTO, F.A. Paisajes cambiantes: la dominación Inka en el valle Calchaquí Norte (Argentina). Rev. do Museu de Arqueologia e Etnologia. São Paulo, Suplemento 3: 143-157, 1999.

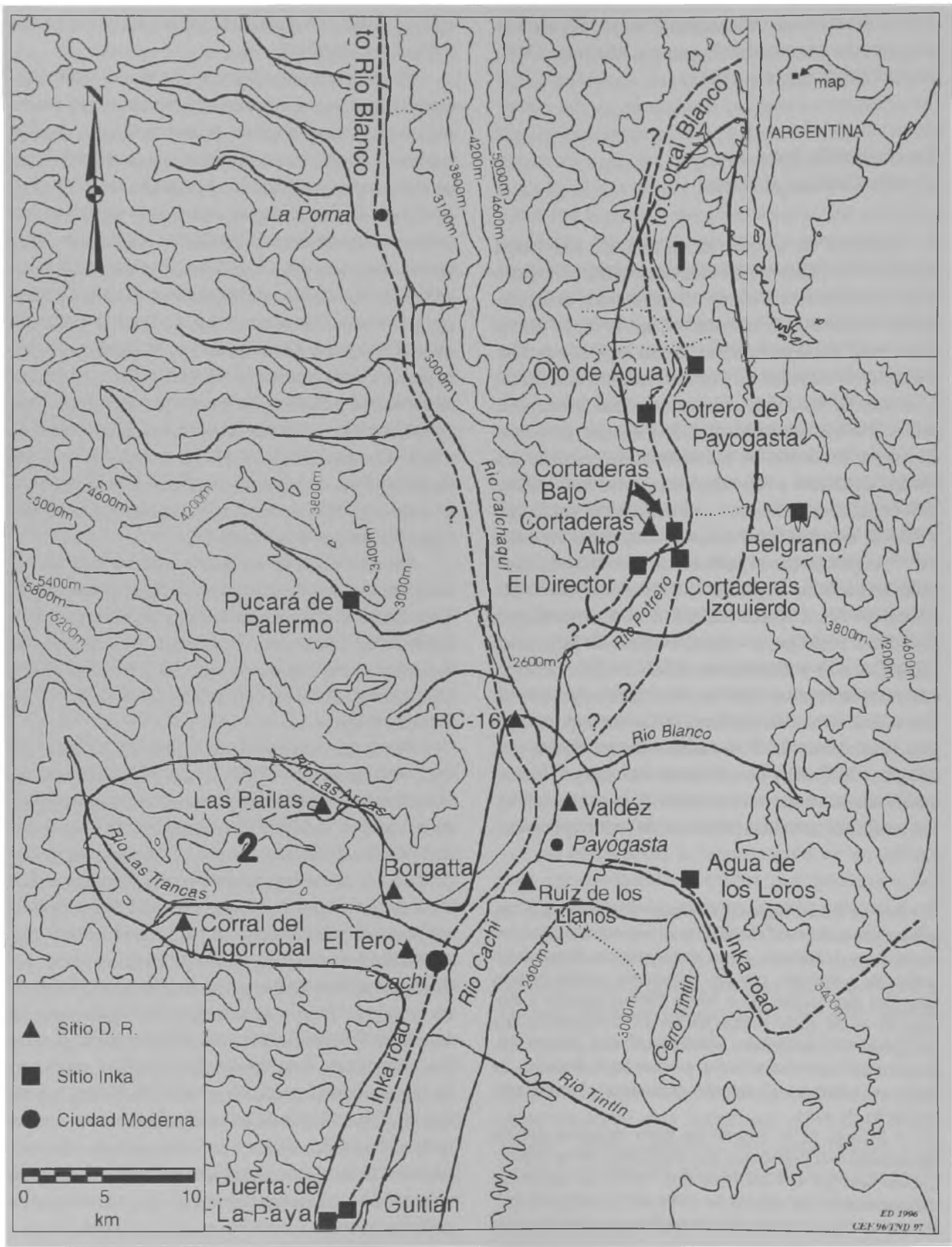

Fig. 1 - Mapa de la región de estudio. 1. Sector en donde se emplazaron los principales asentamientos Inkas. 2. Sector en donde se localizaron los principales poblados locales. 
ACUTO, F.A. Paisajes cambiantes: la dominación Inka en el valle Calchaquí Norte (Argentina). Rev. do Museu de Arqueologia e Etnologia, São Paulo, Suplemento 3: 143-157, 1999.

En contraste con la ocupación Inka en la región, la ocupación de la sociedad local del Período Tardío ${ }^{6}$ fue marcadamente distinta. Esta sociedad ocupó principalmente el sector medio del valle Calchaquí (Figura 1), principalmente los alrededores del poblado actual de Cachi, y especialmente en la fértil área de Cachi Adentro (río Las Arcas y río Las Trancas). Allí concentraron la gran mayoría de sus asentamientos y construyeron los poblados de mayor tamaño y complejidad, 7 que van desde 10 hasta algunos de más de 50 hectáreas (Tarragó y Díaz 1972, 1977; Díaz 1983, 1992).

Por su parte, en sectores norte de la región, la ocupación local tardía es reducida, no habiendo destacadas concentraciones poblacionales, y limitándose a pequeños sitios compuestos por unos pocos conjuntos residenciales (patios y recintos asociados) y asociados a parcelas de cultivo (DeMarrais 1997), probablemente ocupados por una o dos unidades domésticas.

Por otro lado, y como se ha señalado más arriba, en el valle del río Potrero, donde la ocupación Inka se concentró, la instalación de poblados locales tardíos fue casi inexistente (Hyslop y Díaz 1983, Hyslop 1984). Sin embargo, existió en esta área un importante sitio local tardío de características defensivas y localizado estratégicamente en la cima de un cerro a 250 metros de altura, desde donde se tiene una importante vista de la región. Dicho asentamiento fortificado, denominado Cortaderas Alto (9 hectáreas), se encuentra localizado prácticamente en la entrada de acceso al valle del río Potrero (D'Altroy y Williams 1998, Acuto 1998). Es interesante que a la misma altura, pero sobre el valle Calchaquí,

(6) Este período es el inmediatamente anterior al Período Inka, con un rango temporal que va desde aproximadamente el 1000 al $1470 \mathrm{AD}$ (Ottonello y Lorandi 1987). Es importante destacar que cuando escribo por ejemplo "sitio tardío" hago referencia a un asentamiento ocupado durante este período.

(7) Por ejemplo, entre los más importantes: La Paya y Guitián sobre la margen derecha del río Calchaquí a aproximadamente $11 \mathrm{~km}$ al sur de Cachi; Fuerte Alto (SSalCac 4), Tero (SSalCac 14) y Mariscal en los alrededores de Cachi; Borgatta (SSalCac 16), Choque, Las Pailas (SSalCac 18) en la quebrada de las Arcas en el área de Cachi Adentro; Loma del Oratorio, Copa (SSalCac 25), Corral del Algarrobal (SSalCac 27) en la quebrada de las Cuevas en el área de Cachi Adentro; Ruiz de los Llanos (SSalCac 10), Valdez, Buena Vista (SSalCac 87) en la margen izquierda del valle Calchaquí, entre muchos otros (Tarragó y Díaz 1972, 1977; Díaz 1983, 1992). se instaló también otro asentamiento fortificado de características similares llamado Pucará de Palermo (Ardissone 1940). Si tenemos en cuenta que el centro poblacional de la sociedad tardía se encontraba más al sur, y seguramente también ese era el centro de sus cabeceras políticas ${ }^{8}$ y de sus actividades económicas; ${ }^{9}$ entonces podemos pensar que estos dos sitios con semejantes características hayan servido como una línea de defensa de las comarcas de más al sur. Quizá esta línea constituyó la frontera del territorio ocupado por la sociedad tardía local antes de caer bajo el dominio del Imperio Inka. De este modo, podemos suponer que el área en donde se instalaron los Inkas habría sido una región marginal o una frontera para la sociedad local tardía.

Ahora bien, volviendo al tema de la llegada de los Inka al valle Calchaquí Norte, ¿cuales son las razones que han llevado al Imperio a realizar esta ocupación diferencial en la región?, o mejor dicho, ¿en relación a qué aspectos de las estrategias de dominación implementadas por los Inkas en la región atendió esta especial organización en la ocupación del área?. Por otra parte, ¿por qué los Inkas establecieron sus asentamientos alejados de los grandes poblados locales y en un área aparentemente marginal del territorio de la sociedad tardía local?

Generalmente, cuando se trata de explicar la lógica de la ocupación Inka en una región, otras investigaciones tienden a señalar que los Inkas emplazaron sus poblados en relación a los recursos que venían a captar: tierras de cultivo, minerales, mano de obra etc.

En el caso del valle Calchaquí Norte y sus alrededores los Inkas no habrían establecido sus asentamientos precisamente en relación a los campos de cultivo. Las tierras de cultivo cercanas a los dos principales sitios Inkas de la región (Potrero de Payogasta y

(8) La sociedad local del Período Tardío ha sido caracterizada como con una organización política de jefatura (González y Pérez 1972, Ottonello y Lorandi 1987). Para el momento de la conquista española las fuentes etnohistóricas señalan que las cabeceras políticas de los grupos étnicos de este sector del valle Calchaquí que estamos estudiando se encontraban en algún lugar cercano al poblado actual de Cachi (Lorandi y Boixados 1987-88).

(9) Vale señalar que en esa zona es donde se concentró la explotación agrícola para ese momento, evidenciada por la destacada presencia de canchones de cultivo prehispánicos. 
ACUTO, F.A. Paisajes cambiantes: la dominación Inka en el valle Calchaquí Norte (Argentina). Rev. do Museu de Arqueologia e Etnologia, São Paulo, Suplemento 3: 143-157, 1999.

Cortaderas) no son las más abundantes ni las más fértiles de la región, siendo además algo escasa el agua. Por el contrario el mayor porcentaje de tierras cultivables de la zona, las de mejor calidad y las de mayor disposición de agua, se localizan más al sur (Figura 1), en los alrededores del poblado actual de Cachi y en la zona de Cachi Adentro (río Las Trancas y río Las Arcas). Precisamente en donde se localizaba la mayor concentración poblacional durante el Período Tardío.

Los arqueólogos argentinos han postulado que uno de los objetivos de la conquista inkaica sobre el Noroeste Argentino estuvo centrada en la búsqueda de minerales, especialmente el cobre (por ejemplo González 1980, 1982; Raffino 1981, 1979-82; entre otros). Sin embargo, según los mapas mineros actuales de esta región, la zona del valle del río Potrero, en donde se concentro la ocupación Inka (con sus sitios más importantes) no presenta minas de minerales potencialmente explotables por los Inkas, tales como cobre, oro, plata. Estos recursos sí se presentan en zonas aledañas, aunque alejadas a más de $60 \mathrm{~km}$, como en el norte de la quebrada del Toro, en los alrededores del cerro Acay (donde se inicia el valle Calchaquí), así como en áreas más distantes como la Puna.

Por último, y en lo que respecta a establecerse cerca del recurso humano, si bien sí dominaron la región y a sus habitantes, tal como demuestra la arqueología y dicen las fuentes etnohistóricas, los Inkas, como ya señalé, no se instalaron directamente en relación con la población local. ${ }^{10}$

Por otra parte, algunos investigadores (Strube 1963, Murra 1978:183) indican que las razones de que el Imperio haya situado sus sitios alejados de los poblados locales tuvo que ver con su intención de no incidir negativamente en la economía y la supuesta autosuficiencia de las comunidades andinas por ellos dominadas. ${ }^{11}$ Supuestamente al

(10) Cabe señalar que esta idea de que los Inkas buscaban un control cercano y estrecho de las poblaciones locales tiene que ver con que la principal fuente de financiamiento imperial surgía de la tributación en trabajo o mita que exigían a las comunidades sometidas (Murra 1978).

(11) Los investigadores andinos han sostenido durante muchos años que una de las particularidades de las sociedades prehispánicas de los Andes fue su autosuficiencia a través de un complejo sistema de acceso directo a distintos nichos ecológicos (denominado modelo de verticalidad) en donde conseguían los recursos necesarios para su reproducción biológica y social (Murra 1975). levantar sus poblados en zonas alejadas evitaban que, por ejemplo, los ejércitos arrasasen los asentamientos locales.

Podemos también pensar que la estrategia Inka de ocupación diferencial sobre esta área del valle Calchaquí tenga que ver con una cuestión diacrónica. Es decir que estas diferencias estén dadas por diferencias temporales en las estrategias de ocupación Inka de los valles. Por ejemplo que hayan ocupado la región norte en un primer momento, durante la conquista y consolidación de la dominación, y que una vez que el dominio se hubo establecido y que la posibilidad de conflictos con las sociedades locales se hubiera reducido, las instalaciones imperiales comenzaron a realizarse en las zonas más densamente ocupadas por las poblaciones locales (en el sector medio del valle), así como sobre algunos de los centros locales (como en La Paya y Guitián). Esta idea se podría sostener si pensamos que siempre la ocupación de un territorio con grupos fuertemente establecidos y a los que hay que dominar puede ser más arriesgada. Para instalar edificios y posiblemente funcionarios imperiales en el medio de un asentamiento local, se debe contar con garantías de seguridad dadas por una dominación ya bastante consolidada. Sin embargo, por ahora esta idea no parece encajar con los pocos fechados que se tienen (D'Altroy y Williams 1995). Al parecer los sitios Inkas del sector norte, no sólo fueron ocupados durante las primeras etapas de la llegada del Imperio al valle, sino a lo largo de todo el Período Inkaico y hasta la caída del Imperio.

Teniendo todas estas cuestiones en mente, quisiera en este punto desarrollar una interpretación completamente distinta y que creo podría explicar esta situación. En primer lugar considero que la ubicación de los sitios Inkas no tuvo mucho que ver con la localización de los recursos o poblaciones y la búsqueda de una cercanía y control directo sobre éstos.

A mi parecer una de las intenciones del Imperio al ubicar sus asentamientos más destacados, y con ellos la mayoría de las actividades políticas y económicas más importantes realizadas por los Inkas en la región, alejados de la zona de ocupación local, fue concebir un paisaje diferente y propio donde el espacio fue reestructurado en relación a las necesidades imperiales de dominación.

La creación de este nuevo paisaje construido constituyó, a través de su materialidad y de su sig- 
nificación, un poderoso mecanismo de dominación y control que apuntó principalmente a imponer nuevas relaciones y prácticas sociales sobre las poblaciones locales. Esto, posiblemente significó, en cierto sentido, una "re-socialización" y una toma de conciencia de la nueva distribución del poder por parte de estas poblaciones. La inédita estructura del paisaje, desarrollada en mi opinión a partir de principios de estructuración relacionados con la distribución del poder, tuvo que haber sido al mismo tiempo apoyada por una "re-educación" (tal vez a través de mecanismos de coerción) de los habitantes locales para transformarlos en agentes competentes en el uso de la nueva espacialidad, su materialidad y la decodificación de sus signos y símbolos.

Uno de los principales cambios que debió haber producido la instalación de los centros inkaicos en un área que antes había sido marginal económicamente, y que al parecer pudo haber sido una frontera del territorio de la sociedad tardía local, tuvo haber tenido que ver sin duda con una transformación en la localización espacial del poder político en la región. Los nuevos centros de poder y dominación regional ya no se encontraban en sectores medios del valle, sino que aparecían instalados en una zona de la que la sociedad local había hecho poco uso. Sin temor a equivocarnos, podemos pensar que los Inkas re-significaron el paisaje social de los valles Calchaquíes, modificando significativamente las imágenes espaciales mentales de sus pobladores, así como la percepción que éstos tenían de su espacialidad. Lo que antes había sido margen y frontera pasaba a ser centro con la llegada del Imperio. Centro que concentraba gran parte del poder político y era foco de dominación, al que se debía tributar en trabajo y con el cual la élite local debía negociar su jerarquía.

Es muy posible también que el acceso a este paisaje "inkaizado" haya sido restringido para los pobladores locales, como al parecer lo fue la circulación por la red vial instalada por los Inkas a lo largo de su vasto Imperio (Hyslop 1984).

Por otra parte, es importante destacar que la estructuración del espacio en los asentamientos inkaicos es muy diferente a la de los sitios locales. Por lo tanto, si tenemos en cuenta que los Inkas exigían a sus vasallos tributo en trabajo (Murra 1978), y de acuerdo a nuestras ideas de que las principales actividades del Imperio en la región se realizaban con mano de obra local ${ }^{12}$ en el área del valle del río Potrero (Earle 1994; D'Altroy et al. ms.; Acuto 1994, 1998); entonces podemos pensar que los grupos que eran llevados allí para trabajar, o también aquellos que iban por alguna actividad en especial (por ejemplo: ceremonias en las que era invitada la élite local), se encontraban con un ambiento construido completamente diferente al que estaban acostumbrados, con significados nuevos que debían aprender y al que eran obligados a adaptarse. Los pobladores locales tuvieron que empezar a hacerse competentes en su comportamiento en esos lugares: por donde circular, por donde no, que podían usar y que no, con quienes se podían relacionar y con quienes no. ${ }^{13}$

La competencia en el comportamiento en los centros imperiales, por parte de las poblaciones locales, debió haberse logrado con el tiempo y la rutina. Por lo tanto, es posible que la gente local que los Inkas instalaron en sus asentamientos fuese establecida allí de manera fija para trabajar para el Imperio, ${ }^{14}$ es decir que no rotasen con otros habitantes locales.

Ahora bien, ¿qué pasaba con la presencia Inka más al sur, en el sector medio del valle Calchaquí, lugar en donde se ubicaban los grandes poblados

(12) En este punto es importante destacar que existen varios casos que demuestran que los Inkas muchas veces utilizaban en sus principales centros mano de obra traída de otros lugares del Imperio y no a la población local (por ejemplo Lorandi y Cremonte 1991, Williams y Cremonte 1992-93). (13) Los Inkas construyeron en sus centros regionales una serie de estructuras particulares, algunas inéditas en los asentamientos locales, tal como: la kallanka (edificio de uso administrativo y para hospedaje de funcionarios imperiales), el ushnu (una especie de plataforma en donde se sentaba en ciertos acontecimientos el gobernante imperial), la plaza (espacio público formalizado en donde se realizaban fiestas y ceremonias que reproducían la supuesta "hospitalidad" que el Imperio tenía para con sus dominados), etc. Sin duda, los habitantes locales tuvieron que aprender el significado y el uso de estas construcciones, así como el acceso que ellos podían tener a las mismas.

(14) Cortaderas es uno de los dos centros Inkas más importantes erigidos en este sector de la región. Existe en este sitio un sector residencial algo apartado (denominado Cortaderas Derecha) que presenta arquitectura local y una ocupación que al parecer empezó con la llegada de los Inkas a la región (Acuto 1998). Tal vez este sector haya sido el lugar en donde habitaban los pobladores locales que trabajaban directamente en esta área del valle en donde los Inkas se establecieron. Por el momento estamos investigando este punto. 
de la sociedad local? Por supuesto que toda la región fue dominada por el Imperio Inka, sin embargo en este sector la influencia inkaica sobre sus habitantes era distinta con respecto a los que iban a vivir a los sitios imperiales. Estos centros locales habían perdido el poder político y parte de la organización de las actividades económicas. La élite que allí habitaba debió haber tenido que negociar con los gobernantes inkaicos su nueva posición. Se había levantado en esta región una nueva estructura de relaciones de poder, con los Inkas como el centro.

La presencia inkaica en este sector no pasó por una reorganización del espacio, sino más bien por la incorporación de nuevos significados y símbolos relacionados con el Imperio, cuya expresión material debió haber sido la cerámica, los objetos suntuarios de diseño imperial y los edificios instalados dentro de poblados locales (por ejemplo: la Casa Morada). Estos objetos de producción y diseño imperial, seguramente debieron reemplazar a sus símiles locales en los diferentes contextos sociales de uso, y sin duda debieron haber influido y modificado de manera sustancial las prácticas sociales en las que intervenían.

\section{Conclusiones}

En resumen se puede manifestar que la instalación Inka en el valle Calchaquí Norte, y sus valles y quebradas aledañas, implicó una búsqueda de una diferenciación con la organización espacial previa. Los Inkas modificaron el espacio socialmente construido (espacialidad) de la región, no sólo a nivel de su materialidad sino también en cuanto a su significación. El Imperio Inka construyó en un área prácticamente deshabitada un paisaje propio (con sus asentamientos, edificios y símbolos) de estilo y diseño típicamente inkaico.

Con el arribo de los Inkas el paisaje cambió y se resignificó. El poder político no solamente cambió de manos sino que también se modificó su localización en el paisaje. La llegada del Imperio impli- có transformaciones en las relaciones y las prácticas sociales (actividades económicas, rituales, estatus), y sin duda la nueva estructuración del paisaje debió haber sido básica para promover y ayudar a fijarlas. Es decir, considero que la manipulación del espacio debió haber sido de fundamental importancia en la generación de aquellas prácticas y relaciones sociales que el Imperio deseaba imponer, siendo por lo tanto un mecanismo fundamental de dominación.

Lo se quiere expresar con estos párrafos, es que los Inkas podrían haberse instalado en el área media del valle y haber desarrollado las mismas actividades económicas que en el sector norte. Sin embargo, al afincarse en el sector norte lograron estructurar un paisaje propio, que debió haber modificado la percepción previa del espacio y generar ciertas acciones y comportamientos en los agentes que allí concurrían. Si los Inkas buscaban producir y reproducir ciertas prácticas sociales, nada mejor crear un nuevo paisaje, re-socializar a la gente y hacerla competente en esas prácticas a través del espacio (como agente socializador y estructurante). Además podían generar también un mayor control, en los espacios por ellos creados, sobre la gente que iba a trabajar en sus asentamientos

Por último, si tenemos en cuenta que esta instalación separada de la previa se da en varios otros casos, podemos pensar que la política de creación de un nuevo paisaje diferente del de las sociedades dominadas, buscando principalmente cambiar el foco de poder y como mecanismo de dominación, pudo haber sido una política centralmente planificada.

\section{Agradecimientos}

A los organizadores de la 1ra. Reunión Internacional de Teoría Arqueológica en America del Sur, Pedro P. Funari y Eduardo Neves (mi primo querido) por su cordial y amistoso trato. A Marisa Lazzari por ayudarme a aclarar varias ideas. 
ACUTO, F.A. Paisajes cambiantes: la dominación Inka en el valle Calchaquí Norte (Argentina). Rev. do Museu de Arqueologia e Etnologia, São Paulo, Suplemento 3: 143-157, 1999.

\section{Bibliografía}

ACUTO, F.

1994 La organización del almacenaje estatal: La ocupación Inka en el sector norte del valle Calchaqui y sus alrededores. Tesis para optar al grado de Licenciado en Ciencias Antropológicas, orientación Arqueología. Facultad de Filosofía y Letras, Universidad de Buenos Aires, inédita.

1996 Tambos en la niebla. Acerca de dos casos de instalaciones inkaicas en el noroeste argentino. $\mathrm{Pa}$ limpsesto, Revista de Arqueología $\mathrm{N}^{\circ} 5$.

1998 Economía Inka en el sitio de Cortaderas: Primeras interpretaciones. Relaciones de la Sociedad Argentina de Antropología. Buenos Aires. En prensa.

ARDISSONE, R.

1940 La instalación indígena en el Valle Calchaquí, a propósito del Pucará de Palermo. Anales del Instituto de Etnografía Americana, Buenos Aires, I:169-89.

BÁRCENA, R.

1988 Investigaciones de la dominación incaica en Mendoza. El Tambo de Tambillos, la vialidad anexa y los altos cerros cercanos. Espacio, Tiempo y Forma, Revista de la Facultad de Geografía e Historia, Serie I Prehistoria, Madrid, T. 1: 397-426.

BARNES, T.; GREGORY, D.

1997 Place and landscape. T. Barnes; D. Gregory (Eds.) Reading Human Geography. Londres, Arnould: 292-98.

BENDER, $B$.

1993 Introduction: Landscape - Meaning and action. B. Bender (Ed.) Landscapes: Politics and Perspectives. Oxford, Berg Publisherds Ltd: 1-17.

BOURDIEU, $\mathbf{P}$

1985 La producción y reproducción de la lengua legítima. ¿Qué significa hablar?, Capítulo 1. Madrid, Akal.

1977 Outline of a theory of practice. Cambridge: Cambridge University Press.

\section{COSGROVE, $D$.}

1997 Prospect, perspective and the evolution of the landscape idea. T. Barnes; D. Gregory (Eds.) Reading Human Geography. Londres, Arnould Ed: $324-42$.

D'ALTROY, T.; HASTORF, C.; LORANDI, A.; WILLIAMS, V.; EARLE, T.; HAGSTRUM, M.; SANDEFUR, E.; CALDERARI, M.; DEMARRAIS, E.; DANIELS, R.; RUSELL, G.

Inka Imperial rule in the Valle Calchaquí, Argentina. Sometido al Journal of Latin American Antiquity. Ms.

D'ALTROY, T.; WILLIAMS, V.

1995 Informe sobre los fechados radiocarbónicos del Proyecto Arqueológico Calchaquí. Manuscrito presentado al Ministerio de Educación y Cultura, provincia de Salta, Argentina. Ms.
1998 The 1997 field research of the Proyecto Arqueológico Calchaquí. Ms.

De LORENZI, M.; DÍAZ, P.

1976 La ocupación incaica en el sector septentrional del valle Calchaquí. Actas y Memorias IV Congreso Nacional de Arqueología Argentina (primera parte). Revista del Museo de Historia Natural de San Rafael (Mendoza) II, Mendoza (1/4): 75-88.

De MARRAIS, E.

1997 Materialization, Ideology and Power: The Development of Centralized Authority among preHispanic Polities of the Valley Calchaqui, Argentina. Ph.D. Dissertation, University of California, Los Angeles.

DÍAZ, P

1983 Sitios arqueológicos del valle Calchaquí. Estudios de Arqueología, Museo Arqueológico de Cachi, Cachi, 2: 93-104.

1992 Sitios arqueologicos del valle Calchaquí IV.Estudios de Arqueología, Museo Arqueológico de Cachi, Cachi, 5: 63-77.

EARLE, $T$.

1994 Wealth finance in the Inka Empire: Evidence from the Calchaquí valley, Argentina. American Antiquity, 59 (3): 443-460.

EDHOLM, F.

1993 The view from below: Paris in the 1880s. B. Bender (Ed.) Landscapes: Politics and Perspectives. Oxford, Berg Publisherds Ltd: 13968.

ENTRIKIN, J.N.

1997 The betweenness of place. T. Barnes; D. Gregory (Eds.) Reading Human Geography. Londres, Arnould Ed.: 299-314.

FOSTER, S.

1989a Analysis of spatial patterns in buildings (access analysis) as an insight into social structure: Examples from the Scottish Atlantic Iron Age. Antiquity, 63: 40-50.

1989b Transformations in social space: The Iron Age of Orkney and Caithness. Scottish Archaeological Review, 6: 34-55.

FOUCAULT, M.

1976 Vigilar y castigar. Siglo Veintiuno Editores. GIDDENS, A.

1979 Central problems in Social Theory. Londres: MacMillan Press Ltd.

1981 A contemporary critique of Historical Materialism. Londres: MacMillan Press Ltd.

1995 La constitución de la sociedad. Bases para la teoría de la estructuración. Buenos Aires: Amorrortu Editores.

GONZÁLEZ, A.R.

1980 Patrones de asentamiento incaico en una provincia marginal del Imperio: implicaciones socioculturales. Relaciones de la Sociedad Argentina de Antropología, Buenos Aires, XIV (1): 63-82. 
ACUTO, F.A. Paisajes cambiantes: la dominación Inka en el valle Calchaquí Norte (Argentina). Rev. do Museu de Arqueologia e Etnologia, São Paulo, Suplemento 3: 143-157, 1999.

1982 Las "provincias" Inca del antiguo Tucumán. Revista del Museo Nacional, Lima, XLVI: 317380.

GONZÁLEZ, A.R.; PÉREZ, J.

1972 Argentina Indígena, visperas de la conquista. Buenos Aires: Paidós.

GREGORY, D.; URRY, J. (Eds.)

1985 Social relations and spatial structures. Londres: MacMillan Press Ltd.

HILLIER, B.; HANSON, J.

1984 The social logic of space. Cambridge: Cambridge University Press.

HODDER, I.

1994 Interpretación en arqueología. Barcelona: Editorial Crítica, segunda edición ampliada y puesta al día.

HYSLOP, J.

1984 The Inka road system. New York: Academic Press.

1990 Inka settlement plannig. Austin: University of Texas Press.

1993 Factors influencing the transmission and distribution of Inka cultural materials throughout Tawantinsuyu. D. Rice (Ed.) Latin American Horizons. Washington, D.C., Dumbarton Oaks Research Library and Collection: 337-56.

HYSLOP, J.; DÍAZ, P.

1983 El camino incaico: Calchaquí-Tastil (N.O. Argentino). Gaceta Arqueológica Andina. Instituto de Estudios Andinos, Lima, 1-6: 6-8.

JARMAN, N.

1993 Intersecting Belfast. B. Bender (Ed.) Landscapes: Politics and Perspectives. Oxford, Berg Publisherds Ltd.: 107-38.

KÜCHLER, S.

1993 Lanscape as memory: The mapping of process and its representation in a Melanesia society. B. Bender (Ed.) Landscapes: Politics and Perspectives. Oxford, Berg Publisherds Ltd.: 85-106.

LAWRENCE, D.; LOW, S.

1990 The built environment and spatial form. Annual Review of Anthropology, 19: 453-505.

LEFEBVRE, $\mathrm{H}$.

1974 La production de l'espace. Paris: Anthropos. LOCOCK, $M$.

1994 Meaningful architecture. M. Locock (Ed.) Meaningful architecture: Social interpretations of buildings. Avebury, World Wide Archaeology Series: 1-13.

LORANDI, A.M.; BOIXADÓS, R.

1987 Etnohistoria de los Valles Calchaquíes en los

1988 siglos XVI y XVII. Runa, Buenos Aires, XVIXVII: 263-419.

LORANDI, A.; CREMONTE, B.

1991 Evidencias en torno a los mitmaqkunas incaicos en el N.O. Argentino. Anthropológica, 9: 212-36.

McGUIRE, $\mathbf{R}$.

1991 Building power in the cultural landscape of Broome County, New York 1880 to 1940. R.H. McGuire; R. Paynter (Eds.) The Archaeology of Inequality, Cambridge, Blackwell: 102-24.
MILLER, D.; ROWLANDS, M.; TILLEY, C.

1989 Introduction. D. Miller; M. Rollands; C. Tilley (Eds.) Domination and Resistance. London, Routledge: 1-26.

MURRA, J.

1975 El control vertical de un máximo de pisos ecológicos en la economía de las sociedades andinas. Formaciones económicas y políticas del mundo andino, Lima, IEP: 59-115.

1978 La organización económica del Estado Inca. Buenos Aires, Editorial Siglo XXI.

OTTONELLO, M.; LORANDI, A.M.

1987 Introducción a la Arqueología y Etnología. Buenos Aires: Eudeba.

PARKER PEARSON, M.; RICHARDS, C.

1994 Ordering the world: Perceptions of architecture, space and time. M. Parker Pearson; C. Richards (Eds.) Architecture and order. New York, Routledge: 1-37.

PAYNTER, R.; McGUIRE, R.

1991 The Archaeology of Inequality: Material Culture, Domination, and Resistance. R.H. McGuire; R. Painter (Eds.) The Archaeology of Inequality. Cambridge, Blackwell: 1-27.

RAFFINO, $\mathbf{R}$.

1978 La ocupación Inka en el N.O.A.: Actualización y perspectivas. Relaciones de la Sociedad Argentina de Antropología, Buenos Aires, XII.

1981 Los Inkas del Kollasuyu. La Plata, Argentina: Ramos Americana Editora.

RAFFINO, R.; RAVIÑA, G.; IACONA, L.; OLIVERA, D.; ALBORNOZ, A

1979 Aplicaciones de la teoría de sistemas y propues-

1982 ta taxonómica de los vestigios inkas en los Andes meridionales. Cuadernos del Instituto $\mathrm{Na}$ cional de Antropología, Buenos Aires, 9: 5976.

ROSE, G.

1997 Looking at landscape: The uneasy pleasures of power. T. Barnes; D. Gregory (Eds.) Reading Human Geography. Londres, Arnould Ed.: 342-354.

SHANKS, M.; TILLEY, C.

$1987 R e$-constructing archaeology. Londres y New York: Routledge.

SMITH, A.; DAVID, N.

1995 The production of space and the house of Xidi Sukur. Current Anthropology, 36 (3): 441-71.

SOJA, E.

1985 The spatiality of social life: Towards a transformative retheorisation. D. Gregpry; J. Urry (Eds.) Social relations and spatial structures. London, MacMillan: 90-127.

1996 Thirdspace: journeys to Los Angeles and other real-and-imagined places. London: Blackwell Publishers.

\section{STEADMAN, S.}

1996 Recent research in the archaeology of architecture: beyond the fundations. Journal of Archaeological Research, 4 (1): 51-93. 
ACUTO, F.A. Paisajes cambiantes: la dominación Inka en el valle Calchaquí Norte (Argentina). Rev. do Museu de Arqueologia e Etnologia, São Paulo, Suplemento 3: 143-157, 1999.

STRUBE, E.

1963 Vialidad imperial de los Incas. Desde Colombia hasta Chile central o sur de Mendoza, con inclusión de sus proyecciones orientales. Universidad Nacional de Córdoba. Facultad de Filosofía y Humanidades. Instituto de Estudios Americanistas: Serie Histórica, XXXIII. Córdoba.

TARRAGO, M.; DÍAZ, P.

1972 Sitios arqueológicos del valle Calchaquí. Estudios de Arqueología, Museo Arqueológico de Cachi, Cachi, 1: 49-61.

1977 Sitios arqueológicos del valle Calchaquí (II). Estudios de Arqueología, Museo Arqueológico de Cachi, Cachi, 2: 63-71.

THOMAS, J.

1993 The politics of vision and the archaeologies of landscape. B. Bender (Ed.) Landscapes: Politics and Perspectives. Oxford, Berg Publisherds Ltd.: 19-48.

WEBER, $M$.

1997 Economía y Sociedad. Madrid: Alianza Editorial.

WILLIAMS, $\mathrm{V}$.

1983 Evidencia de actividad textil en el establecimiento incaico de Potrero-Chaquiago (Pcia. de Cata- marca). Relaciones (N.S) Buenos Aires, XV: 49-59.

1991 Control estatal incaico en el noroeste argentino. Un caso de estudio: Potrero-Chaquiago (Pcia de Catamarca). Arqueología, Revista de la Sección Prehistoria del Instituto de Ciencias Antropológicas, Buenos Aires, 1: 75-103.

WILLIAMS, V.; CREMONTE, B.

1992/ Mitmaqkuna o circulación de bienes?. Indi-

1993 cadores de la producción ceramica como identificadores étnicos. Un caso de estudio en el noroeste argentino. Avances en arqueologia, Instituto Interdisciplinario de Tilcara, FFyL, 2: 9-21.

WILLIAMS, V.; LORANDI, A.M.; D'ALTROY, T.; HASTORF, C.

1995 Informe de avance del Proyecto Arqueológico Calchaquí (Campañas 1990-92). Volumen Homenaje a Pio Pablo Díaz, Andes: Antropología e Historia. Revista CEPIHA, Facultad de Humanidades, Universidad Nacional de Salta.

ZUKIN, S

1991 Landscapes of power. California: University of California Press. 